\title{
L1 Transfer and Chinese as Second Language Learners' Comprehension of Noun-Noun Compounds
}

\author{
YANG Shu-yi \\ The University of Iowa, Iowa, USA
}

\begin{abstract}
L1 transfer is an important topic in second language acquisition (SLA). This study explored whether the two features in noun-noun compounds (position of modifier and head, expression of semantic relations) follow the pattern predicted by FT/FA Hypothesis. One hundred and twenty low and high proficiency level learners with English and Thai as their L1s participated in this study. They were asked to interpret 24 Chinese noun-noun compounds within which 12 words shared the same noun-noun expression in Chinese, English, and Thai (MADE OF) while the other 12 shared the same expression only in Chinese and English (LOCATED and HAS). Results showed that L1 English learners at low proficiency level outperformed their L1 Thai counterparts in overall comprehension and particularly in interpretation of words of LOCATED semantic relation; while L1 Thai learners performed the same as English L1 learners in words of HAS semantic relation, suggesting that L1 transfer is affected by input frequency. L1 Thai learners made a great progress as their L2 proficiency improved, indicating that learners can reset the target language features. Findings from the qualitative analysis of the interpretations given by participants were consistent: L1 Thai learners offered more deviating interpretations than their L1 English counterparts. Pedagogical recommendations were made about Chinese noun-noun compound instruction.
\end{abstract}

Keywords: Chinese noun-noun compounds, Full Transfer/Full Access Hypothesis (FT/FA Hypothesis), position of modifier and head, expression of semantic relations

\section{Introduction}

There has long been a proliferation of studies on the effect of L1 transfer on L2 acquisition. The studies were guided by a number of theoretical and pedagogical proposals which include, but are not limited to, Schwartz and Sprouse's (1996) Full Transfer/Full Access Hypothesis (FT/FA Hypothesis). The empirical findings so far have been largely inconclusive. On the other hand, recent second language acquisition (SLA) research has seen a noticeable increase of interest in L2 vocabulary processing, yet there still remains a lack of attention to noun-noun compound comprehension.

In this paper, first the author will review the research conducted within the framework of FT/FA Hypothesis. In the sections that follow, she will present the characteristics of position of modifier and head and expression of semantic relations in three languages this study will focus: Chinese, English, and Thai. Then the author will report the findings of an experiment that tested the validity of FT/FA Hypothesis in the comprehension of Chinese noun-noun compounds.

YANG Shu-yi, teaching assistant, Ph.D. student, Asian \& Slavic Languages and Literatures, The University of Iowa. 


\section{Full Transfer/Full Access Hypothesis}

It is undeniable that L1 transfer exists in L2 acquisition (Corder, 1967; Gass, 1996; R. Ellis, 1997; Weinreich, 1953; Kellerman \& Sharwood-Smith, 1986; Odlin, 1989; Zobl, 1984). However, debates continue to persist about how learners' L1 works. Several theories and hypotheses have been constructed, such as Contrastive Analysis Hypothesis (Lado, 1957), Markedness Theory (Eckman, 1977; Kellerman, 1978, 1979), and Processibility Theory (Pienemann, 1998).

As Universal Grammar has been widely accepted, some transfer hypotheses based on Universal Grammar have been put forward. According to Full Transfer/Full Access Hypothesis (FT/FA Hypothesis) presented by Schwartz and Sprouse (1996), all features of L1 including all the possible categories and functional values will be transferred to interlanguage at the initial stage. As learners improve in their L2 proficiency, they can reset features of target language based on L2 input therefore the role of L1 will dwindle.

\section{Full Transfer: Initial State}

The first prediction of FT/FA Hypothesis is that, all L1 features including functional and lexical categories as well as all possible feature values and strengths will be transferred to interlanguage at the initial state of L2 acquisition.

Evidence from studies on syntactic order has been provided. For example, Haznedar (1997) reported that a 4-year-old Turkish learner of English overwhelmingly used Turkish style verb-final constructions instead of verb-initial ones in his early interlanguage, suggesting L1 transfer was taking place. In her studies of French-speaking young learners of English, White $(1991,1992)$ found that the early interlanguage of these learners allowed the adverb in between the verb and direct object, showing the features of adverb and verb position in their L1. Leung (2005) focused on the acquisition of adjective and noun position of Vietnamese- and Cantonese-speaking learners of French. Results revealed that L1 Vietnamese learners outperformed their L1 Cantonese counterparts in their French oral production, confirming the occurrence of L1 transfer since Vietnamese and French share the same adjective-final order. Chinese SLA researchers (H. ZHU \& ZENG, 2010; Y. M. LIN, 2000; SHI, 2008; CHEN, 2002; H. Y. LIN, 2008; R. H. ZHU, 2011) conducted contrastive and error analysis to show that learners of head-modifier L1s (e.g., Portuguese, Indonesian, Thai, and Vietnamese) often put modifier behind head when they started to acquire modifier-head Chinese.

Although L1 transfer is more detectable in the acquisition of syntactic order, some scholars also noticed L1 role in the lexical order in noun-noun compounds. Nicoladis $(1999,2002)$ conducted a series of studies on bilingual children's performance of modifier and head position in compounds. In a case study of a French/English bilingual child, she found that the positioning of modifier and head was influenced by both languages. Nicoladis (2002) expanded her sample of participants to $25 \mathrm{French} /$ English bilingual children and 25 English monolingual children. The participants were asked to name pictures in a production task and identify certain objects among pictures in a comprehension task. Results showed that bilingual children produced more compounds in reverse order than monolingual children did while their comprehension were similar, indicating that L1 transfer works differently in production and comprehension. Following the similar paradigm, Foroodi-Nejad and Paradis (2009) investigated the effect of L1 word order on Persian/English bilingual children's production of novel noun-noun compounds. Persian compounds are mainly modifier-final while English compounds are head-final. Sixteen Persian/English bilingual children, 19 Persian monolingual children, and 17 English monolingual children completed a picture naming task. It revealed that bilinguals 
produced far fewer head-final compounds than English monolinguals and far fewer modifier-final compounds than Persian monolinguals, representing the transfer of both languages.

As for the L1 role in L2 expression, studies have demonstrated a facilitative effect in L2 vocabulary acquisition when L1 and L2 share a large number of cognates (Ard \& Hombury, 1983; Hasselgren, 1994; Gollan, Forster, \& Frost, 1997) or homographs (Y. Y. ZHU, 1996; G. W. HE, 1998; QUAN, 2004). It has been proved that different expressions of the same semantic relation would affect learners' selection preference to the certain word or construction (Jarvis, 2000, 2009; Pavlenko, 2002; Pavlenko \& Driagina, 2007; Pavlenko \& Jarvis, 2002). Hohenstein, Eisenberg, and Naigles (2006) found that Spanish/English bilinguals tended to select verbs with path information while English monolinguals were more likely to choose verbs with mode information. Jarvis (2000) also argued that Finnish- and Swedish-speaking learners of English used different content words when identifying definite objects or events. Findings from Laufer and Eliasson (1993) and Sjöholm (1995) suggested that learners of L1 lacking verbal constructions preferred single-verb forms when acquiring an L2 with verbal constructions. Having compared the acquisition of English definite pronoun of a Spanish- and a Chinese-speaking child, Zobl (1982) reported that the Spanish-speaking child could produce correct English definite pronouns at a very early stage while the Chinese-speaking child often used demonstrative pronouns of similar function due to the lack of definite pronouns in Chinese.

The different ways of expression in L1 also affect L2 compound acquisition. The main word formation mechanism varies across different languages. Compounds through the combination of word roots are common in Germanic languages (e.g., English) while propositional structures are often adopted in Romance languages (e.g., French). Therefore, English-French bilingual children in Nicoladis (1999) produced more compound errors in French than in English tasks due to the absence of the compounding expression in French. Likewise, Bongartz (2002) examined the strategies of creating compounds by L1 Czech and Chinese learners of English, with phrases dominating the word formation in Czech while compounds more common in Chinese. Results demonstrated that learners displayed preference congruent with the main word formation pattern in their L1s.

However, there are also some studies against the statement of full transfer in initial state. For example, researchers claimed that many syntactic features such as subject-verb agreement (Johnston, 1997), negation (YUAN, 2004), and wh-question (YUAN, 2007; Y. ZHANG, 2008) are not transferred in L2 early stage. Regarding the syntactic order, Kawaguchi (2002) examined L1 English L2 Japanese learners' production and failed to detect the transfer of SVO order from L1 English. Hakansson, Pienemann, and Sayehli (2002) also reported that Swedish-speaking children did not transfer INV order in their L1 to their L2 German. In her research on a French/English bilingual child, Nicoladis (1999) found that although in French adjective is placed after noun while in English the opposite is true, the accuracy of adjective position of this young participant was as high as $90 \%$ in both languages, indicating little effect of $\mathrm{L} 1$ features.

In sum, there are more studies supporting full transfer in initial state, covering the fields of both syntax and lexis acquisition. Research against the prediction concentrates on syntax. This study will further test the prediction using noun-noun compounds as experimental materials.

\section{Full Access: Feature Reset}

Another prediction of FT/FA Hypothesis is that, L2 input will trigger the reset of L1 features and L1 effect will decrease gradually. A series of studies on pro-drop (White, 1985, 1986; Hilles, 1986; Cancino, Rosansky, \& Schumann, 1978) demonstrated that although learners transferred L1 pronoun features initially, they would 
adjust their interlanguage and acquire L2 features.

Word order features can also be reset. Flynn (1996) investigated the acquisition of relative clause of L1 Japanese learners of English and argued that learners could overcome the negative L1 transfer of head-final order. In Jansen, Lalleman, and Muysken's (1981) study on Turkish- and Moroccan-speaking learners of Dutch, errors of verb-final and verb-second order common among beginners almost disappeared in advance learners, indicating the weakening of L1 role. However, the reset only starts when L2 input provides counterevidence. Camacho (1999) analyzed free oral production of L1 Southern Quechua learners of Standard Spanish. There are two features that require reset: null object with definite antecedent and object movement based on sentence focus. Results revealed that high level learners successfully acquired the second feature but failed to reset the first one since there is no corresponding counterevidence in L2 input.

In terms of expression features, it has been evidenced that L1-like expression gradually disappears with L2 development. For example, the ability to distinguish cognates or homographs in L1 and L2 enhances as learners develop their L2 (ZHAO, 2011; B. LI, 2011). Moreover, the gap between learners of different L1s caused by L1 transfer has narrowed as learners advance in their L2 (Ringbom, 1987, 2007). Having compared the use of single verb and verbal phrase by L1 Swedish and Finnish learners in L2 English, Sjöholm (1995) claimed that the different preference noticed in beginners disappeared in advanced learners.

Evidence against the prediction of feature reset also exists. The strongest opposition comes from the research of fossilization, a phenomenon that L1 lexical, syntactic and other rules and features persist in the interlanguage of even advanced learners (Selinker, 1972). Early errors continue to emerge during the later stage (Mukattash, 1986; LONG, 1997; DONG, 2012) and high level learners still rely heavily on their L1 (MacWhinney, 2005, 2008; JIANG, 1999, 2002, 2004).

To summarize, there have been more studies for rather than against full access in later stage. Since FT/FA Hypothesis does not predict the final state of L2 acquisition (Sprouse, 2011), the counterevidence from fossilization research is far less persuasive. This study attempts to examine the change of L1 transfer during different stages rather than to describe the final state of interlanguage.

This study will investigate the validity of the two predictions proposed by FT/FA Hypothesis in L2 Chinese noun-noun compound comprehension. The two target features are the position of modifier and head and the expression of semantic relations, which will be elaborated in the following sections.

\section{Position of Modifier and Head}

According to linguistic typology, first proposed by Greenberg (1966), human languages fall into three categories in terms of the basic word order: VSO, SVO, and SOV. The position of modifier (including genitive, adjective, and relative clause) and head can be inferred from the 45 universal rules and observed from cross language investigations. In VSO and SVO languages, genitive, adjective, and relative clause all follow the head noun (NG, NA, NRel). By contrast, in SOV languages, genitive and relative clause always precede the head noun (GN, RelN) while adjective can be placed before and after the head noun (AN or NA). In summary, in VO languages (VSO and SVO), the common order is head-modifier. In OV languages (SOV), on the contrary, modifier often precedes head (CAO, 1996).

There remains controversial whether Chinese is an SVO or SOV language (TAI, 1975; C. N. LI \& Thompson, 1974; LIU, 2003). Despite the inconclusiveness, Chinese linguists have reached the agreement that modifier-head is the dominant order in Chinese (WANG \& XIAO, 1981; SHEN, 1996; Z. G. ZHANG, 1956). 
Genitive (1a, 1b, 2a, 2b), adjective (3a, 4a), and relative clause (5a, 5b) always precede the head noun. In occasional cases, it is grammatical to have adjective after the head noun $(3 \mathrm{~b}, 4 \mathrm{~b})$, often with a special purpose of intensifying the modifier.

$$
\begin{aligned}
& \text { Example (1a) } \text { 这是我的房子。 } \\
& \text { This is my house. } \\
& (1 b) \text { *这是房子我的。 } \\
& \text { *This is house my. } \\
& \text { Example (2a) } \text { 他是我弟弟。 }
\end{aligned}
$$

He is my younger brother.

(2b) *他是弟弟我。

*He is younger brother my.

Example (3a) 雪白的墙壁

snow-white wall

(3b) ? 墙壁雪白的

?wall snow-white

Example (4a) 红苹果

red apple

(4b) ?苹果红

?apple red

\section{Example (5a) 那个喜欢吃苹果但是不喜欢吃香蕉的女孩}

that like to eat apples but dislike to eat bananas girl

(5b) *那个女孩喜欢吃苹果但是不喜欢吃香蕉的

*that girl like to eat apples but dislike to eat bananas

In terms of Chinese noun-noun compounds, the modifier-head order still holds. For example, 牛奶 (cow's milk) is a kind of drink, with the modifier 牛 (cow) preceding the head 奶 (milk). While 奶牛 (cow) is a kind of animal, with the modifier 奶 (milk) preceding the head 牛 (cow).

English is an SVO language, with a quite flexible modifier position. Generally speaking, short and simple-structured modifier often precedes the head noun, such as genitive and adjective in the form of a single word. Long and complex-structured modifier follows the head noun, such as adjective-complement structure and relative clause (J. M. LI, 2010; B. LI \& REN, 2006). In English, it is grammatical and equally frequent to have genitive both before (GN) and after (NG) head noun (Rosenbach, 2008).

Example (6a) the box's cover

(6b) the cover of the box

Adjective-noun order is dominant in English. But in some circumstances, adjective can or must be put after the noun (XIONG, 1996) including in adjective-complement structure (e.g., a man suitable for the job), collocation (e.g., secretary general), paired adjective (e.g., people, both old and young). Because of its long and complex structure, relative clause often follows head noun ( $7 \mathrm{a}, 7 \mathrm{~b})$.

Example (7a) the person who is good at playing piano

(7b) *the good at playing piano person

As for noun-noun compounds, modifier-head order is the convention in English (e.g., iron bowl).

In contrast, Thai is a typical SVO language, with a head-modifier order. Genitive, adjective, and relative 
clause must follow the head noun (8a, 8b, 9a, 9b, 10a, 10b).

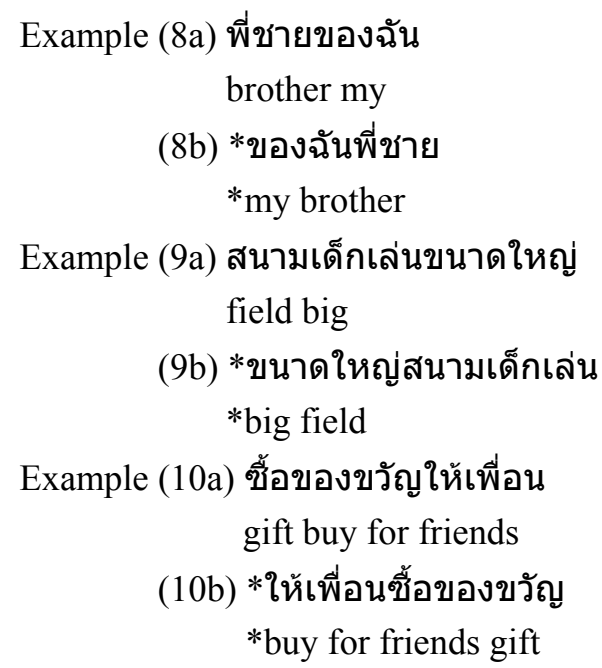

By far, there have been few studies on Thai noun-noun compounds. D. M. HE (2012) pointed out that noun-noun compounds account for a large proportion of compounds in Thai and still follow the head-modifier order (F. X. HE, 1991; M. Z. ZHANG, 1991; SHU, 2010).

The features of the position of modifier and head in Chinese, English, and Thai noun-noun compounds are listed in Table 1.

Table 1

Position of Modifier and Head in Three Languages

\begin{tabular}{|l|l|}
\hline Language & Position of modifier and head \\
\hline Chinese & Modifier-Head \\
\hline English & Modifier-Head \\
\hline Thai & Head-Modifier \\
\hline
\end{tabular}

\section{Expression of Semantic Relations}

To express the MADE OF relation, in Chinese, De structure (11a) and noun-noun compound (11b) could be both adopted; in English, propositional structure (12a) and noun-noun compound (12b) could be used; in Thai, noun-noun compound (13a) is the common expression.

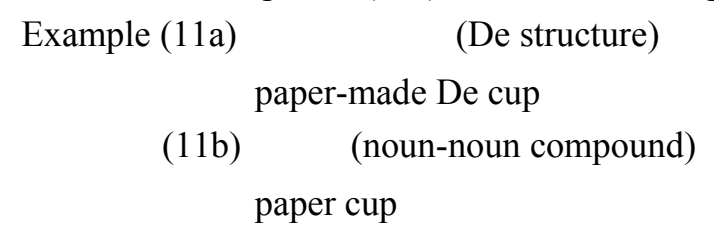

Example (12a) a cup made of paper (propositional structure)

(12b) a paper cup (noun-noun compound)

Example (13a) ถ้วยกระดาษ (noun-noun compound) cup paper

As for HAS relation, in Chinese, De structure (14a) and noun-noun compound (14b) could be both adopted; in English, possessive structure (15a), propositional structure (15b) and noun-noun compound (15c) could be used; in Thai, only propositional structure (16a) could be employed. 


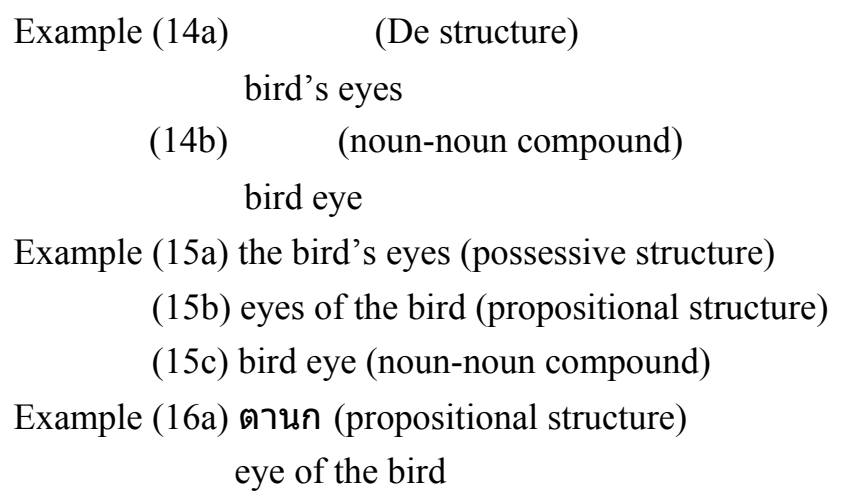

In terms of LOCATED relation, in Chinese, positional structure (17a), propositional structure (17b), and noun-noun compound $(17 \mathrm{c})$ could be adopted; in English, propositional structure (18a) and noun-noun compound (18b) could be used; in Thai, only propositional structure (19a) could be used.

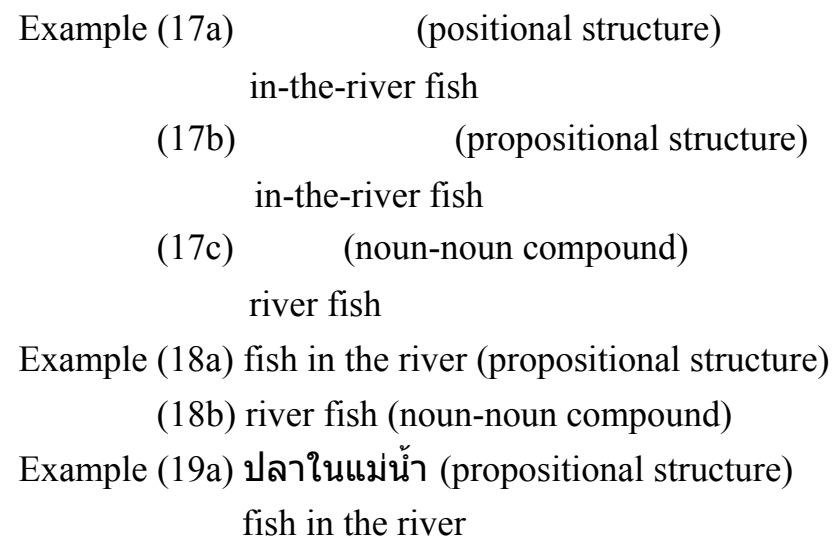

The possibility to use noun-noun compound to express the three semantic relations in Chinese, English, and Thai is shown in Table 2. Noun-noun compounds for the three semantic relations are acceptable in both Chinese and English while in Thai only the semantic relation of MADE OF can be expressed through noun-noun compounds. In other words, Chinese and English share the same expression mechanism in all three semantic relations while Thai has a different mode of expression in HAS and LOCATED relations.

Table 2

Possibility to Express Three Semantic Relations in Noun-Noun Compounds

\begin{tabular}{|l|l|l|l|}
\hline Language & MADE OF & HAS & LOCATED \\
\hline Chinese & $\sqrt{ }$ & $\sqrt{ }$ & $\sqrt{ }$ \\
\hline English & $\sqrt{ }$ & $\sqrt{ }$ & $\sqrt{ }$ \\
\hline Thai & $\sqrt{ }$ & $\times$ & $\times$ \\
\hline
\end{tabular}

As mentioned above, the position of modifier and head as well as the expression of semantic relations vary across languages. According to FT/FA Hypothesis, learners' L1 features regarding word order and expression will influence their comprehension of noun-noun compounds at early stage and L1 transfer will gradually dwindle as learners improve their L2 proficiency. Thus it is logical to speculate that the impact of L1 on comprehension could be different for learners at different L2 levels. The following study will investigate such effects by systematically comparing L2 learners' interpretation of Chinese noun-noun 
compounds. The specific objectives are: (1) to determine whether Chinese as second language (CSL) learners of an L1 with modifier-head order outperform those of an L1 with head-modifier, (2) to explore whether CSL learners of an L1 which shares the same expression of semantic relations outperform those of an L1 which does not, and (3) to examine the extent to which L2 proficiency contributes to the divergence among learners of diverse L1s.

\section{Method}

\section{Participants}

One hundred and twenty CSL learners from Beijing Language and Culture University, Minzu University of China, and Beijing Foreign Studies University participated in this study. Among them there are $60 \mathrm{~L} 1$ English learners (38 males and 22 females, average age: 21$)$ and $60 \mathrm{~L} 1$ Thai learners (18 males and 42 females, average age: 18$)$.

A Chinese Character Amount Test was designed for L2 proficiency classification in addition to taking learning time, class placement, and teaching materials used into consideration. Fifty test characters were selected randomly from the first 3,000 characters in Modern Chinese Character Frequency Form (State Language Affairs Commissions, 1992). Participants were asked to write down pinyin and make a word for each character. Correct rate was calculated with 1 point for correct pinyin and word, 0.5 point for correct pinyin or word, 0 point for wrong pinyin and word or no answer.

Participants with 0 to 10 points were identified as low level learners while those with more than 10 points as high level learners. There are 30 low-level and 30 high-level learners for each L1 group. The mean scores of participants were shown in Table 3.

Table 3

The Mean Chinese Character Amount Test Scores of Participants (Points)

\begin{tabular}{llc}
\hline L1 background & L2 proficiency & Character amount \\
\hline \multirow{2}{*}{ English } & Low (30) & $6.97(1-10)$ \\
& High (30) & 17.63 (above 10) \\
\multirow{2}{*}{ Thai } & Low (30) & $8.37(1-10)$ \\
& High (30) & 19.08 (above 10) \\
\hline
\end{tabular}

To ensure the presumed difference in L2 proficiency, a two-tailed $t$-test on the scores was performed. The two groups of different L2 proficiency for both English and Thai as L1 learners differed significantly, $t(58)=$ $-10.160, p=0.000, t(58)=-8.796, p=0.000$, with high level learners significantly outperforming low level learners.

Thirty Chinese native speakers (15 males and 15 females, average age: 24.5 ) also participated in this study, serving as the guideline. They were graduate students from Shanghai and Beijing.

\section{Materials}

Twenty-four novel noun-noun compounds were constructed. All compounds were created through changing one morpheme of a common Chinese word selected from HSK Vocabulary Level Syllabus (Chinese Proficiency Test Center in Beijing Language and Culture University, 2000) without changing semantic relations (e.g., 马奶 horse's milk was created by changing 牛 cow in 牛奶 cow's milk with 马 horse. Still 马奶 is HAS relation just as 牛奶). Twenty-four compounds were divided into three semantic relations: 
MADE OF (12 items), HAS (six items), and LOCATED (six items). Some examples were listed in Table 4 (All items could be seen in the Appendix).

Table 4

Examples of Noun-Noun Compounds

\begin{tabular}{|l|l|}
\hline Expression of semantic relations & Examples \\
\hline MADE OF (Same) & 石门 stone gate \\
\hline HAS (Different) & 兔毛 rabbit's fur \\
\hline LOCATED (Different) & 河鱼 river fish \\
\hline
\end{tabular}

To minimize the effects of familiarity and morphological complexity, word frequency and stroke number were calculated for each item. Results of the word frequency and stroke number count could be seen in Table 5 . The mean word frequency and stroke number of items of three semantic relation types were tested by a one-way analysis of variance (ANOVA). The three types of compounds showed no significant difference in word frequency, $F(2,15)=0.209, p=0.814$, or stroke number, $F(2,15)=0.178, p=0.839$.

Table 5

Characteristics of Materials

\begin{tabular}{lll}
\hline Expression of semantic relation & Word frequency & Stroke number \\
\hline MADE OF (Same) & 34.83 & 16.75 \\
HAS (Different) & 40.17 & 12.83 \\
LOCATED (Different) & 29.00 & 14.33 \\
\hline
\end{tabular}

To ensure that Chinese characters did not hinder participants' understanding, explanations of all morphemes were provided. Six filler items that were common Chinese compounds of LOCATED, FOR, and MADE OF semantic relations were also provided. All items were placed randomly.

\section{Procedure}

Chinese native speakers were asked to write down the meaning of each item in comprehension test. L2 learners first completed Chinese Character Amount Test and then took the comprehension test in which both Chinese and their L1 could be used. The percentage of the modifier-head interpretations was collected as data. Each participant performed the task individually.

\section{Results}

The mean percentage of modifier-head interpretations of four groups was shown in Table 6. A three-way analysis of variance (ANOVA) was performed with L1 background (Thai vs. English) and L2 proficiency (low vs. high) as the between-subject factors and expression of semantic relations (MADE OF vs. HAS vs. LOCATED) as the within-subject factor. The main effect for L1 background was significant, $F(1,116)=$ 12.514, $p=0.001$, with L1 Thai learners providing far fewer modifier-head interpretations than their L1 English counterparts. The main effect for L2 proficiency was significant, $F(1,116)=15.204, p=0.000$, with high level learners outperforming low level learners. The main effect for expression of semantic relations was also significant, $F(2,232)=39.169, p=0.000$. Post hoc pair wise comparisons revealed that HAS compounds were better interpreted than MADE OF $(p=0.000)$ and LOCATED compounds $(p=0.000)$, and MADE OF compounds were better interpreted than LOCATED compounds $(p=0.000)$. 
Table 6

Percentage of Modifier-Head Interpretations of L2 Learners (\%)

\begin{tabular}{lllll}
\hline \multirow{2}{*}{ L1 background } & \multirow{2}{*}{ L2 proficiency } & \multicolumn{3}{c}{ Expression of semantic relation } \\
\cline { 3 - 5 } & & MADE OF (Same) & HAS (Different) & LOCATED (Different) \\
\hline \multirow{2}{*}{ Thai } & Low & 64.45 & 77.78 & 31.94 \\
\multirow{2}{*}{ English } & High & 70.56 & 93.89 & 51.11 \\
& Low & 67.22 & 77.78 & 66.67 \\
& High & 83.33 & 94.44 & 77.22 \\
\hline
\end{tabular}

The analysis showed a significant interaction between $\mathrm{L} 1$ background and expression of semantic relations, $F(2,232)=20.527, p=0.000$. Simple effect analysis was conducted. For MADE OF compounds (same expression for Chinese, English, and Thai), no significant difference surfaced between English and Thai as L1 learners, $F(1,118)=1.78, p=0.185$. For HAS compounds (same expression for Chinese and English, different for Chinese and Thai), there was no significant difference between the two groups of learners, $F(1,118)=0.00$, $p=0.952$. For LOCATED compounds (same expression for Chinese and English, different for Chinese and Thai), L1 English learners interpreted significantly better than L1 Thai learners, $F(1,118)=29.13, p=0.000$.

Other interactions were not significant (L1 background and L2 proficiency: $F(2,232)=0.008, p=0.929$; L2 proficiency and expression of semantic relation: $F(2,232)=0.053, p=0.819$; L1 background, L2 proficiency, and expression of semantic relation: $F(2,232)=0.475, p=0.492)$. A graphic representation was shown in Figure 1.

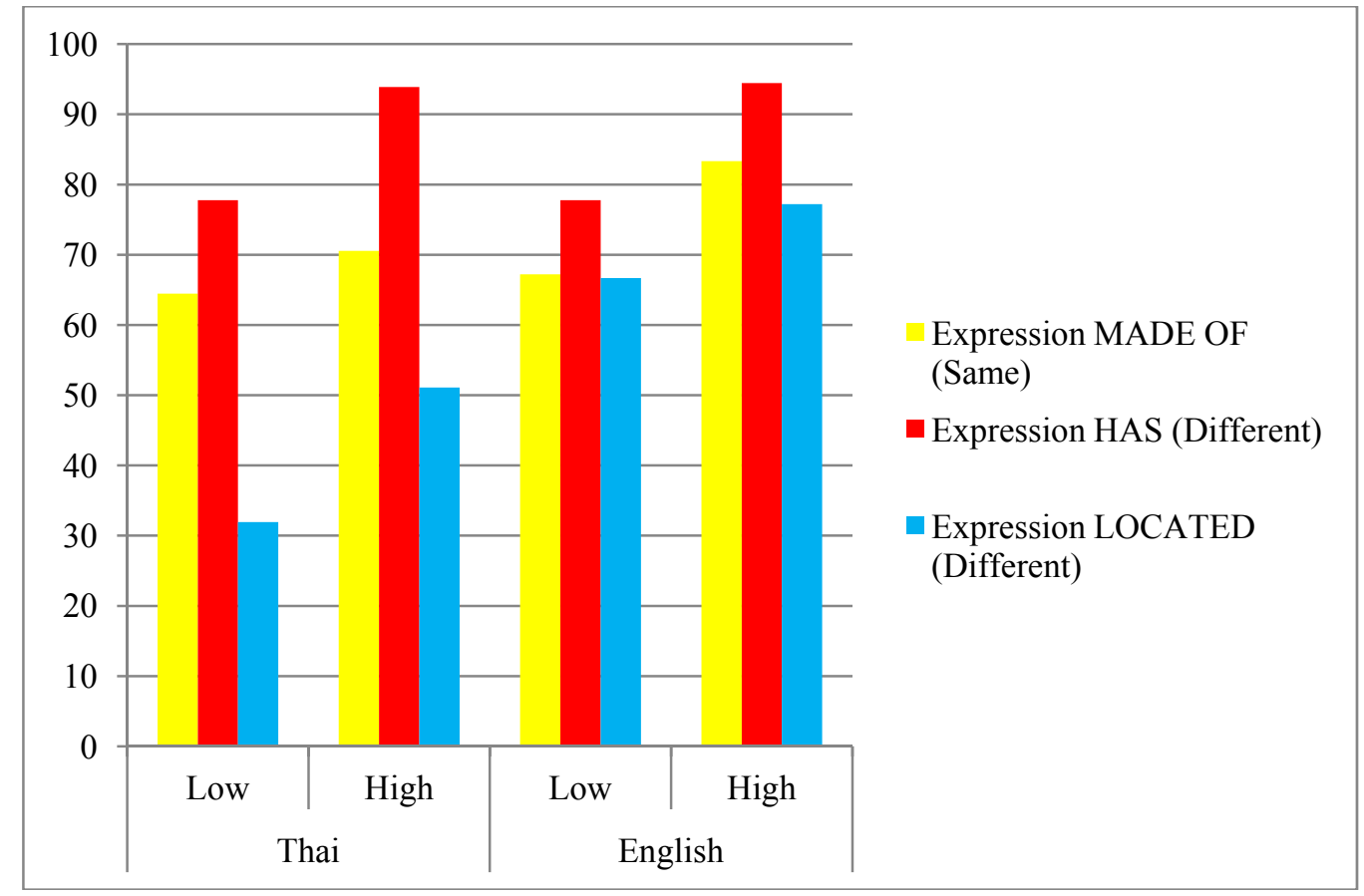

Figure 1. Percentage of modifier-head interpretations of L2 learners (percentage).

The interpretations given by L2 learners were further analyzed. Five categories were classified (see Table 7) for deviating interpretations. The first category is to explain only one morpheme in the compound. For example, some participants interpreted 山牛 (mountain bull) into 牛 (bull). Another type of interpretation is to explain the compound based on a joint semantic relation between the two morphemes instead of a 
modifier-head relation. For example, a number of L2 learners simply interpreted 山牛 (mountain bull) into a combination of mountain and bull (山和牛: mountain and bull). The third category is to use other semantic relations to connect the two morphemes. For example, several participants relied on PROPERTY relation and interpreted 山牛 (mountain bull) into 山形状的牛 (mountain-shaped bull). The fourth type is to interpret based on a reversed order of morphemes. For example, instead of comprehending 山牛 (mountain bull) as a kind of bull, many participants believed it as a kind of mountain (e.g., 有很多牛的山: mountain with a lot of bulls). The last group of explanation is either difficult to understand or hard to cluster into any mentioned type. For example, one participant provided an interpretation of 很大 (very big) for 山牛 (mountain bull).

Table 7

Classification of Deviating Interpretations

\begin{tabular}{llrc}
\hline Types of interpretations & Examples & Thai L1 & English L1 \\
\hline Explain only one morpheme & 山牛 (mountain bull): 牛 (bull) & 12 & 23 \\
Joint morpheme interpretation & 山牛 (mountain bull): 山和牛 (mountain and bull) & 13 & 24 \\
Other semantic relations & 山牛 (mountain bull): 山形状的牛 (mountain-shaped bull) & 27 & 36 \\
Order reverse & 山牛 (mountain bull): 有很多牛的山 (mountain with a lot of bulls) & 90 & 14 \\
Other & 山牛 (mountain bull): 很大 (very big) & 15 & 7 \\
Sum & & 157 & 104 \\
\hline
\end{tabular}

It was noticeable that L1 Thai learners gave far more interpretations based on a reversed order than L1 English participants, again confirming the L1 effect of modifier and head position.

The interpretations for each type of semantic relation were also examined. For MADE OF compounds, there were a few, although not many, interpretations of a reversed order for Thai as L1 learners (e.g., 泥墙 mud wall: the mud on the wall; 布伞 cloth umbrella: the cloth that used for making umbrella). Meanwhile, some explanations based on other semantic relations were provided, both from Thai and English as L1 learners (e.g., 纸鞋 paper shoes: light shoes, shoes of poor quality, shoes drawn on the paper; 铁柜 iron cabinet: cabinet for iron storing, heavy cabinet). For HAS compounds, there were only a few deviating interpretations. Both groups of learners tended to explain only one morpheme (e.g., 鸭肉 duck's meat: duck; 兔毛 rabbit's fur: fur). For LOCATED compounds, interpretations of a reversed order accounted for a major part for Thai as L1 learners (e.g., 河鱼 river fish: river that has a lot if fish; 湖泥 lake mud: very dirty lake; 水竹 water bamboo: bamboo's sap, the water that grows bamboos). By contrast, there were few deviating interpretations among English as L1 learners, which mainly for only two compounds 桌报 (desk newspaper: newspaper read on the desk) and 树花 (tree flower: flowers that grow on the tree). The participants often gave a joint morpheme interpretation (e.g., 桌报 desk newspaper: desk and newspaper, reading room; 树花 tree flower: tree and flower).

\section{Discussion}

\section{L1 Effect on L2 Learners' Comprehension of Chinese Noun-Noun Compounds}

The results showed that the feature of modifier and head position in learners' L1 greatly influenced their Chinese noun-noun compound comprehension. Thai as L1 learners, especially beginners, produced much fewer modifier-head interpretations than English as L1 learners, which lends support to the prediction of full transfer in initial state of FT/FA Hypothesis. It was also in consistent with previous L1 transfer studies on word order (Leung, 2005; Nicoladis, 1999, 2002; Foroodi-Nejad \& Paradis, 2009). As an SVO language, Thai has a 
head-modifier word order, leading learners to interpret Chinese words in a similar way. L1 Thai beginners had only $58.06 \%$ of modifier-head interpretations, clearly displaying their L1 features. English as L1 learners, however, produced far more modifier-head interpretations than their Thai counterparts, with the percentage of 70.56\%. The preference to modifier-head interpretations in L1 English learners even at the initial stage could be attributed to the fact that most noun-noun compounds in English follow the modifier-head order.

It was revealed that the $\mathrm{L} 1$ feature of expression of semantic relations also impacted the comprehension of Chinese noun-noun compounds. For MADE OF compounds (same expression for Chinese, English, and Thai), English and Thai as L1 beginners performed similarly. While for LOCATED compounds (same for Chinese and English, different for Chinese and Thai), L1 Thai low level learners fell far behind their L1 English counterparts. The lack of noun-noun compounds as the expression of LOCATED semantic relation in Thai is the main reason for the poor performance, confirmed by the findings that English/French bilingual children made more word order errors in French tasks due to the infrequency of compounding as a word formation mechanism in French (Nicoladis, 1999).

However, for HAS compounds (same for Chinese and English, different for Chinese and Thai), the inferior performance by L1 Thai learners in LOCATED compounds was not seen. Although there are no noun-noun compounds to express HAS semantic relation in Thai, it seemed that Thai as L1 learners did not have difficulty in comprehending these compounds in Chinese. Such results could not be explained by FT/FA Hypothesis and there might be other factors than L1 transfer playing roles. One possibility is that, the frequency of HAS noun-noun compounds in Chinese interacts with L1 transfer. Having calculated the frequency of noun-noun compounds of different semantic relations in HSK Vocabulary Level Syllabus (Chinese Proficiency Test Center in Beijing Language and Culture University, 2000), it suggested that HAS compounds have the highest frequency among all 12 types of compounds, accounting for $21.67 \%$ (see Table 8).

Table 8

Classification of Semantic Relations in Noun-Noun Compounds in HSK

\begin{tabular}{lccccc}
\hline Semantic relation & Grade A & Grade B & Grade C & Grade D & Sum \\
\hline N1 HAS N2 & 6 & 34 & 73 & 100 & $213(21.6 \%)$ \\
N2 HAS N1 & 3 & 9 & 5 & 13 & $30(3.05 \%)$ \\
N1 as Agent & 1 & 4 & 4 & 8 & $17(1.72 \%)$ \\
N2 as Agent & 4 & 4 & 7 & 19 & $34(3.86 \%)$ \\
MADE OF & 12 & 8 & 6 & 21 & $47(4.78 \%)$ \\
METHOD & 5 & 9 & 14 & 10 & $38(3.86 \%)$ \\
FOR & 11 & 23 & 39 & 37 & $110(11.1 \%)$ \\
CONTENT & 10 & 11 & 20 & 25 & $66(6.71 \%)$ \\
LOCATED & 15 & 49 & 10 & 62 & $166(18.9 \%)$ \\
TIME & 13 & 6 & 25 & 20 & $49(4.98 \%)$ \\
IDENTITY/CATEGORY & 13 & 42 & 26 & $74(7.53 \%)$ \\
PROPERTY & 9 & 20 & 285 & 68 & $139(14.1 \%)$ \\
Sum & 102 & 187 & 409 & $983(100 \%)$ \\
\hline
\end{tabular}

According to N. C. Ellis (2002), language processing at all levels is affected by the distribution frequency. Linguistic structures of high frequency are often entrenched in learners' minds because of the high strength of form-meaning mapping (XU, 2012) thus are acquired better and incorporated more easily into the interlanguage (Anderson, 1983). Since HAS compounds repeatedly appeared in L2 input, learners tend to acquire them better 
and faster. In fact, $77.78 \%$ of HAS compounds in this study were correctly interpreted by low level learners of both L1s, implying that acquisition has taken place even in the initial stage in resistant to any L1 effect.

\section{L2 Proficiency Effect on L2 Learners' Comprehension of Chinese Noun-Noun Compounds}

The findings of this study demonstrated that learners made progress in noun-noun compound comprehension as their L2 developed, indicating that learners could reset the features of the target language. The percentage of modifier-head interpretations for high level Thai as L1 learners had climbed to $71.85 \%$, compared to the $58.05 \%$ for low level learners. For LOCATED compounds, L1 Thai learners also improved from only $31.94 \%$ to $51.11 \%$ of interpretations in target-like word order. The enhanced noun-noun compound comprehension due to the accumulating L2 experience provided further evidence to the second prediction of feature reset in FT/FA Hypothesis. This study clearly showed that although they depended on L1 at initial stage, Thai-speaking learners, triggered by L2 input, could reset the features of both modifier-head order and the expression of noun-noun compound for LOCATED semantic relation. However, it is notable that L1 Thai learners still fell behind their English counterparts despite of their high L2 proficiency, especially in LOCATED compounds (L1 English learners: $77.22 \%$ vs. L1 Thai learners: $51.11 \%$ ), indicating that feature reset is a long and difficult process.

\section{Conclusion}

The present study tested the validity of FT/FA Hypothesis on the acquisition of two features: modifier and head position and expression of semantic relations in the context of L2 Chinese noun-noun compound comprehension.

The data demonstrated the following: (1) L1 features were transferred during the initial stage of L2 development. Percentage of target-like interpretations was considerably higher among L2 learners with congruent L1 experience; (2) L2 learners could reset the features as their L2 improved although the reset was a long and difficult process. With the accumulating L2 input, learners with incongruent L1 experience could overcome the negative L1 effect and acquire the target-like structure; and (3) L1 effect on high frequency L2 structures could be minimal even in the initial stage. The strong entrenchment due to the repeated occurrences in L2 input could suppress the potential negative L1 effect.

This study largely confirmed the two predictions of FT/FA Hypothesis, the full transfer in initial state and the feature reset as L2 develops, although some other factors such as L2 input frequency interact with L1 transfer. The results make it plain that L1 experience has significant impacts on L2 word comprehension development, that L2 input is a powerful force in shaping L2 comprehension skills, and, therefore, that individual differences in L2 comprehension efficiency can be explained jointly by L1 and L2 factors. The present findings also render empirical support for the critical role that input frequency plays in comprehension among L2 learners.

The data shed substantial light on comprehension variations among L2 learners and their possible impacts on L2 performance. The finding that L1 experience, L2 proficiency, and certain characteristics of linguistic items jointly affect the performance outcomes has significant implications for classroom practice. Instructional intervention should be designed with the thought that certain linguistic items would not be uniformly difficult to L2 learners with diverse L1 backgrounds. The position of modifier and head as well as the compounding mechanism should be introduced early and emphasized during the whole process of noun-noun compound instruction. 


\section{References}

Anderson, R. (1983). Transfer to somewhere. In S. Gass \& L. Selinker (Eds.), Language transfer in language learning (pp. 177-201). Rowley, MA: Newbury House.

Ard, J., \& Hombury, T. (1983). Verification of language transfer. In S. Gass \& L. Selinker (Eds.), Language transfer in language learning (pp. 157-176). Rowley: Newbury House.

Bongartz, C. (2002). Noun combination in interlanguage: Typology effects in complex determiner phrases. Tubingen, Germany: Niemeyer.

Camacho, J. (1999). From SOV to SVO: The grammar of interlanguage word order. Second Language Research, 15, 115-132.

Cancino, H., Rosansky, E., \& Schumann, J. (1978). The acquisition of English negatives and interrogatives by native Spanish speakers. In E. M. Hatch (Ed.), Second language acquisition: A book of readings (pp. 207-30). Rowley, MA: Newbury House.

CAO, C. S. (1996). Linguistic typology and the debate of Chinese as an SVO or SOV language. Journal of Tianjin Normal University (Social Science), 2, 75-80.

CHEN, Y. H. (2002). The contrast between Indonesian and Chinese in word order and analysis of word order errors of Indonesian-speaking Chinese learners. Journal of College of Chinese Language and Culture of Jinan University, 1, 9-19.

Corder, P. (1967). The significance of learner errors. International Review of Applied Linguistics, 5, 161-170.

DONG, Y. L. (2012). Chinese as a second language learners' acquisition of classifiers (MA dissertation). Peking University, Beijing, China.

Eckman, F. (1977). Markedness and the contrastive analysis hypothesis. Language Learning, 27, 315-330.

Ellis, N. C. (2002). Frequency effects in language processing: A review with implications for theories of implicit and explicit language acquisition. Studies in Second Language Acquisition, 24, 143-188.

Ellis, R. (1997). Second language acquisition. Oxford: Oxford University Press.

Flynn, S. (1996). A parameter-setting approach to second language acquisition. In W. Ritchie \& T. Bhatis (Eds.), Handbook of second language acquisition. San Diego: Academic Press.

Foroodi-Nejad, F., \& Paradis, J. (2009). Crosslinguistic transfer in the acquisition of compound words in Persian-English bilinguals. Bilingualism: Language and Cognition, 12, 411-427.

Gass, S. M. (1996). Second language acquisition and linguistic theory: The role of language transfer. In W. C. Ritchie \& T. K. Bhatia (Eds.), The handbook of second language acquisition (pp. 317-345). San Diego: Academic Press.

Gollan, T. H., Forster, K. I., \& Frost, R. (1997). Translation priming with different scripts: Masked priming with cognates and noncognates in Hebrew-English bilinguals. Journal of Experimental Psychology: Learning, Memory, and Cognition, 23, $1122-1139$.

Greenberg, H. (1966). Universals of language. Cambridge, MA: MIT Press.

Hakansson, G., Pienemann, M., \& Sayehli, S. (2002). Transfer and typological proximity in the context of L2 processing. Second Language Research, 18, 250-273.

Hasselgren, A. (1994). Lexical teddy bears and advanced learners: A study into the ways Norwegian students cope with English vocabulary. International Journal of Applied Linguistics, 4, 237-260.

Haznedar, B. (1997). L2 acquisition by a Turkish-speaking child: Evidence for L1 influence. In E. Hunhes, M. Hughes, \& A. Greenhill (Eds.), Proceedings of the 21st Annual Boston University Conference on Language Development (pp. 245-256). Somerville, MA: Cascadilla Press.

HE, D. M. (2012). The research on Thai word formation (Doctoral dissertation). Shanghai Normal University, Shanghai, China.

HE, F. X. (1991). The comparison of attribute in Chinese and Thai (MA dissertation). Beijing Language and Culture University, Beijing, China.

HE, G. W. (1998). Chinese-root words in Korean and vocabulary instruction. Journal of East China Normal University, 2, 92-94.

Hilles, S. (1986). Interlanguage and the pro-drop parameter. Second Language Research, 2, 33-52.

Hohenstein, J., Eisenberg, A., \& Naigles, L. (2006). Is he floating across or crossing afloat? Cross-influence of L1 and L2 in Spanish-English bilingual adults. Bilingualism: Language and Cognition, 9, 249-261.

Jansen, B., Lalleman, J., \& Muysken, P. (1981). The alternation hypothesis: Acquisition of Dutch word order by Turkish and Moroccan foreign workers. Language Learning, 36, 401-451.

Jarvis, S. (2000). Methodological rigor in the study of transfer: Identifying L1 influence in the interlanguage lexicon. Language Learning, 50, 245-309. 
Jarvis, S. (2009). Lexical transfer. In A. Pavlenko (Ed.), Bilingual mental lexicon: Interdisciplinary approaches (pp. 99-124). Clevedon, UK: Multilingual Matters.

JIANG, N. (1999). Testing processing explanations for the asymmetry in masked cross-language priming. Bilingualism: Language and Cognition, 2, 59-75.

JIANG, N. (2002). Form-meaning mapping in vocabulary acquisition in a second language. Studies in Second Language Acquisition, 24, 617-637.

JIANG, N. (2004). Semantic transfer and development in adult L2 vocabulary acquisition. In P. Bogaards \& B. Laufer (Eds.), Vocabulary in a second language: Description, acquisition, and testing. Amsterdam: Benjamins.

Johnston, M. (1997). Development and variation in learner language (Doctoral dissertation). Australian National University, Canberra, Australian Capital Territory, Australia.

Kawaguchi, S. (2002). Grammatical development in learners of Japanese as a second language. In B. Di Biase (Ed.), Developing a second language (pp. 17-28). Melbourne: Language Australia.

Kellerman, E. (1978). Giving learners a break: Native language intuitions as a source of predictions about transferability. Working Papers on Bilingualism, 15, 59-92.

Kellerman, E. (1979). Transfer and non-transfer: Where are we now?. Studies in Second Language Acquisition, 2, 37-57.

Kellerman, E., \& Sharwood-Smith, M. (1986). Crosslinguistic influence in second language acquisition. New York: Oxford University Press.

Lado, R. (1957). Linguistics across cultures: Applied linguistics for language teachers. Ann Arbor: University of Michigan.

Laufer, B., \& Eliasson, S. (1993). What causes avoidance in L2 learning: L1-L2 differences, L1-L2 similarity, or L2 complexity?. Studies in Second Language Acquisition, 15, 35-48.

Leung, Y. K. I. (2005). L2 vs L3 initial state: A comparative study of the acquisition of French DPs by Vietnamese monolinguals and Cantonese-English bilinguals. Bilingualism: Language and Cognition, 8, 39-61.

LI, B. (2011). The empirical research on morphology effect on Japanese-speaking Chinese learners' vocabulary acquisition. Language Teaching and Linguistic Studies, 5, 65-71.

LI, B., \& REN, H. B. (2006). The contrast analysis of attribute order in English and Chinese and pedagogical implications. Journal of Hexi University, 6, 97-100.

LI, C. N., \& Thompson, S. A. (1974). Historical change of word order: A case study in Chinese and its implications. In J. M. Anderson \& C. Jones (Eds.), Historical linguistics. Amsterdam: North-Holland.

LI, J. M. (2010). The research on comparison of Chinese and English word order within linguistic typology framework. Modern Foreign Language Research, 5, 45-50.

LIN, H. Y. (2008). The comparison of modifier-head structures between modern Chinese and Thai (MA dissertation). Guangxi University, Nanning, China.

LIN, Y. M. (2000). The error analysis and acquisition sequence of Chinese attribute order of Thai-speaking learners (MA dissertation). Beijing Language and Culture University, Beijing, China.

LIU, D. Q. (2003). Linguistic typology and Chinese research. Chinese Teaching in the World, 4, 5-9.

LONG, M. (1997). Fossilization: Rigor mortis in living linguistic system?. Paper presented at SLRF' 97, East Lansing, MI, October.

MacWhinney, B. (2005). A unified model of language acquisition. In J. Kroll \& A. DeGroot (Eds.), Handbook of bilingualism: Psycholinguistic approaches (pp. 49-67). Oxford: OUP.

MacWhinney, B. (2008). A unified model. In P. Robinson \& N. C. Ellis (Eds.), Handbook of cognitive linguistics and second language acquisition (pp. 341-371). London: Routledge.

Mukattash, L. (1986). Persistence in fossilization. International Review of Applied Linguistics, 24, 187-203.

Nicoladis, E. (1999). Where is my brush-teeth? Acquisition of compound nouns in a bilingual child. Bilingualism: Language and Cognition, 2, 245-56.

Nicoladis, E. (2002). What's the difference between toilet paper and paper toiler? French-English bilingual children's crosslinguistic transfer in compound nouns. Child Language, 29, 843-863.

Odlin, T. (1989). Language transfer: Cross-linguistic influence in language learning. Cambridge: CambridgeUniversity Press.

Pavlenko, A. (2002). Bilingualism and emotions. Multilingua, 21, 45-78.

Pavlenko, A., \& Driagina, V. (2007). Russian emotion vocabulary in American learners' narratives. Modern Language Journal, 91, 213-234.

Pavlenko, A., \& Jarvis, S. (2002). Bidirectional transfer. Applied Linguistics, 23, 190-214. 
Pienemann, M. (1998). Language processing and second language development: Processability theory. Amsterdam: John Benjamins.

QUAN, X. L. (2004). An analysis of errors of homographs in Chinese and Korean. Chinese Language Learning, 3, 56-61.

Ringbom, H. (1987). The role of the first language in foreign language learning. Clevedon: Multilingual Matters.

Ringbom, H. (2007). Cross-linguistic similarity in foreign language learning. Clevedon: Multilingual Matters.

Rosenbach, A. (2008). Animacy and grammatical variation: Findings from English genitive variation. Lingua, 118, 151-171.

Schwartz, B. D., \& Sprouse, R. (1996). L2 cognitive states and the full transfer/full access model. Second Language Research, 12, 7-39.

Selinker, L. (1972). Interlanguage. International Review of Applied Linguistics, 10, 209-231.

SHEN, J. X. (1996). Three examples of contrast of English/Chinese grammars. Foreign Language Teaching and Research, 4, 8-13.

SHI, W. Z. (2008). On the negative transfer of the mother tongue through a study of the adverbial transfer of Thai students. Journal of Yunnan Normal University, 3, 59-62.

SHU, H. H. (2010). The comparison of Chinese and Thai modifiers and instructional strategy (MA dissertation). Jinan University, Guangzhou, China.

Sjöholm, K. (1995). The influence of crosslinguistic, semantic and input factors on the acquisition of English phrasal verbs. Abo: Abo Akademi University Press.

Sprouse, R. (2011). The interface hypothesis and full transfer/full access/full parse: A brief comparison. Linguistic Approaches to Bilingualism, 1, 97-100.

TAI, J. (1975). On two functions of place adverbials in Mandarin. Journal of Chinese Linguistics, 3, 154-180.

WANG, K. H., \& XIAO, Y. (1981). The comparison of English and Chinese word order. Foreign Language Teaching and Research, 1, 75-79.

Weinreich, U. (1953). Languages in contact. New York: Linguistic Circle of New York.

White, L. (1985). The pro-drop parameter in adult second language acquisition. Language Learning, 35, 47-62.

White, L. (1986). Implications of parametric variation for adult second language acquisition: An investigation in pro-drop parameter. Oxford: Pergamon Press.

White, L. (1991). Adverbs placement in second language acquisition: Some effects of positive and negative evidence in the classroom. Second Language Research, 7, 133-161.

White, L. (1992). Long and short verb movement in second language acquisition. Canadian Journal of Linguistics, 37, $273-286$.

XIONG, W. H. (1996). The position of attribute, adverbial, and object in Chinese and English. Chinese Teaching in the World, 4 , 69-73.

XU, Q. (2012). The effect of relative frequency on Chinese-speaking English learners' acquisition of prepositional dative constructions. Foreign Language Teaching and Research, 5, 706-718.

YUAN, B. (2004). Negation in French-Chinese, German-Chinese and English-Chinese interlanguages. Transactions of the Philosophical Society, 102, 169-197.

YUAN, B. (2007). Behaviors of wh-words in English speakers' L2 Chinese wh-questions: Evidence of no variability, temporary variability and persistent variability in L2 grammars. Bilingualism: Language and Cognition, 10, 277-298.

ZHANG, M. Z. (1991). The comparison of position of attribute, adverbial, and head in Chinese and Thai (MA dissertation). Beijing Language and Culture University, Beijing, China.

ZHANG, Y. (2008). Adverb-placement and wh-questions in the L2 Chinese of English speakers: Is transfer a structural property or a processing constraint. In J. Kessler (Ed.), Processability approaches to second language development and second language learning (pp. 115-136). Newcastle upon Tyne: Cambridge Scholars Press.

ZHANG, Z. G. (1956). Grammar and grammar instruction. Beijing: People's Education Press.

ZHAO, Y. (2011). L2 acquisition of Chinese lexicon by Korean speaking learners. Chinese Teaching in the World, 3, $412-421$.

ZHU, H., \& ZENG, Z. C. (2010). The error analysis of Chinese word order of Thai students and instructional strategy. Journal of Yunnan Normal University, 6, 78-84.

ZHU, R. H. (2011). The error analysis of Chinese word order of Brazilian students (MA dissertation). Shanxi Normal University, Xi'an, China.

ZHU, Y. Y. (1996). An analysis of homographs in Chinese and Korean from HSK Vocabulary Level Syllabus. Chinese Language Learning, 5, 38-43.

Zobl, H. (1982). A direction for contrastive analysis: The comparative study of development sequences. TESOL Quarterly, 16, 169-83. 
Zobl, H. (1984). Cross-language generalizations and the contrastive dimension of the interlanguage hypothesis. In A. Davies, C. Criper, \& A. P. R. Howatt (Eds.), Interlanguage. Edinburgh: Edinburgh University Press.

\section{Appendix: Materials}

\begin{tabular}{|c|c|c|c|c|c|c|c|}
\hline \multicolumn{8}{|c|}{ Expression of Semantic Relations } \\
\hline \multicolumn{4}{|c|}{ Same for Chinese, English, and Thai } & \multicolumn{4}{|c|}{ Same for Chinese and English, Different for Chinese and Thai } \\
\hline \multirow{13}{*}{ MADE OF } & Compounds & $\begin{array}{l}\text { Word } \\
\text { Frequency }\end{array}$ & \begin{tabular}{|l|} 
Stroke \\
Number
\end{tabular} & \multirow{7}{*}{ HAS } & Compounds & \begin{tabular}{|l|} 
Word \\
Frequency
\end{tabular} & \begin{tabular}{|l|}
$\begin{array}{l}\text { Stroke } \\
\text { Number }\end{array}$ \\
\end{tabular} \\
\hline & 布伞 (Cloth Umbrella) & 9 & 11 & & 兔毛 (Rabbit's Fur) & 103 & 12 \\
\hline & 木棺 (Wood Coffin) & 26 & 16 & & 鸟蛋 (Bird's Egg) & 63 & 16 \\
\hline & 泥墙 (Mud Wall) & 55 & 22 & & 鸭肉(Duck’s Meat) & 26 & 16 \\
\hline & 石门 (Stone Gate) & 63 & 8 & & 马奶 (Horse's Milk) & 42 & 8 \\
\hline & 水冰 (Water Ice) & 9 & 10 & & 鱼牙 (Fish's Teeth) & 1 & 12 \\
\hline & 草纸 (Grass Paper) & 38 & 16 & & 羊角 (Goat's Horn) & 6 & 13 \\
\hline & 棉裤 (Cotton Trousers) & 55 & 24 & \multirow{6}{*}{ LOCATED } & 山牛 (Mountain Bull) & 9 & 7 \\
\hline & 铁柜 (Iron Cabinet) & 25 & 18 & & 河鱼 (River Fish) & 15 & 16 \\
\hline & 铁箱 (Iron Box) & 63 & 25 & & 桌报 (Desk Newspaper) & 81 & 17 \\
\hline & 布帽 (Cloth Hat) & 12 & 17 & & 树花 (Tree Flower) & 35 & 16 \\
\hline & 草床 (Grass Bed) & 18 & 16 & & 湖泥 (Lake Mud) & 11 & 20 \\
\hline & 纸船 (Paper Boat) & 45 & 18 & & 水竹 (Water Bamboo) & 23 & 10 \\
\hline
\end{tabular}

